\title{
Analysis of Implementation Strategy of Cooperative Learning in English Teaching
}

\author{
Li Qian \\ Foreign Language Department, Ankang University, Ankang, 725000, China
}

Keywords: English Teaching; Cooperative learning; Implementation; Strategy

\begin{abstract}
Cooperative consciousness, cooperative spirit and cooperative ability are basic qualities of modern people. With the deepening of English teaching reform, cooperative learning gains acceptance from scholars due to its significant advantages. This paper analyzes the practice effects of cooperative learning in English teaching and discusses credibility and advantages of cooperative learning in English teaching as well as practice strategy of cooperative learning.
\end{abstract}

\section{Introduction}

With the development of economy and improvement of global cooperation mechanism, the communication between the people of all ethnic groups in the world are frequent than before. At this time, fusion of the cultures and customs in the world is strengthened and the relation among countries is closer than before due to changes in economics and trade relations. In this context, only cooperation with each other could be long-term survival in such internationalization development, existing in different conditions. Therefore, the concept of striving for development and cooperative learning is particularly important. The main trend of current international social development is close cooperation with each other, seeking common development and progress. Hence, English teaching and learning shall follow such principal that is more communication in learning and to help each other, resulting in common promotion. Such education mode is conducive to cultivation of students' internationalization strategic vision. Cooperation can promote students communicate with each other and solve doubts, realizing a win-win result. The cultivation of students' cooperative learning spirit by teacher can improve students' English learning ability and improve students’ mutual aid spirit.

\section{The Meaning of Cooperative Learning}

Students have certain difference in learning level and personal ability. Hence random grouping shall be adopted. During specific learning process, teacher is the major guider and student is major participant. And then school evaluates education methods of teachers via scoring each learning team.

\section{The Function of Cooperative Learning in Teaching Learning}

\section{Promote Students' Learning Autonomy Consciousness}

This new education method is taking student as dominant power, which can greatly stimulate students' learning initiative and creative thinking. In this process, students can think and find out independently and can explore jointly and communicate with each other to improve level of learning. Such learning mechanism provides students with a platform to communicate with each other and greatly exert the dominant position of students in learning. In addition, strong interdependence between each other in such system brings great help to cultivate students' self-confidence and self-esteem.

\section{New Mechanism Can Change the Traditional Concept of Teachers and Students}

Under this new learning mechanism, the teacher is a guider instead of traditional docent. The relationship between teachers and students will be broke. They are friends instead of traditional way that is teacher is authority and students shall complete followed. As two important components in 
learning process, teachers and students shall be involved in study actively. Learning through cooperative mechanism emphasizes on that let students have a lot of time and opportunity to think and explore and let students learn from each other by exchanging views and explore each other to improve learning capacity. Under such system, the relationship between teachers and students are equal.

\section{Cooperative Learning Mechanism Creates a Positive Learning Environment for Students}

Under the new system of cooperative learning, students can help each other and improve their learning capacity. On the other hand, before involving in learning method of cooperative mechanism, students study as independent individual and the learning competition is the competition between individuals. However, implementation of such new cooperative mechanism makes competition among students change into competition among different teams. Such competitive mode can greatly improve students' cooperation consciousness and can exchange on learning among students as well as conduct discussion and solve the problems. Team competition brings sense of belonging to students and improves their confidence.

\section{Effective Implementation Strategy of Cooperative Learning in English Teaching}

\section{Rationalization of Structure of Cooperative Group}

The reason for establishing learning group is to promote exchanges among students and to help each other and learn from each other, aiming at making up for their deficiencies. The factors for establishing learning group shall meet reasonability and feasibility. The members of a learning group will direct affect the learning of each member and ultimately affect the performance of such learning group. If members of learning group composed in a reasonable way, it can greatly enhance the students' learning efficiency and bring convenient for teachers to conduct more effective teaching work. Reasonable arrangement in the formation of learning group shall be done, namely, students in different levels with same learning objective. Hence, students can learn from each other and help each other. In addition, teachers shall fully consider gender, hobbies, personal habits, learning ability as well as ability to accept new things and cognitive competence of members and conducts one principal, namely, same in each group and different in one group. Through doing this, students will help each other and achieve fair competition in the daily learning and life, resulting in arousing the enthusiasm for learning. On the other hand, teachers should also consider gender difference, making in a balancing proportion that can promote complementary action. In addition, teachers can organize corresponding activities to cultivate students' ability for bear the responsibility and let students handle things in harmony and mutual help, playing team spirit and achieving team objective. There are differences between the learning groups due to some reasons. To be fair, teachers shall group the existed groups after some time to ensure each group in a same learning level and to improve sense of competition. Each group shall have a team leader who has high sense of responsibility, being in charge of all the things of this group and organizing discussion and analysis to find out problems. Meanwhile, such team leader shall report to teacher about achievements made by them to ensure that learning ability and efficiency can be improved significantly.

\section{Improvement of Learning Content Quality}

In order to strengthen the sense of competition, teachers can take English vocabulary test in the classroom or let students to read English article in a fast and accurate way. In practice, teachers can organize competition of radio message reception by hand in English, English poetry recitation contest and homemade greeting cards in English or performance of drama according to textbooks to promote interest in English, which can enhance mutual collaboration between team members and enhance sense of group honor, aiming at common improving English learning ability.

The teacher should encourage cooperation among students in learning. In addition, the homework shall be from easy to difficult, which let students learn from low level to high level. Such difficult 
shall not be changed considerably, or learning initiative will be cracked down. After a certain time interval, responsibilities and tasks of members can be exchanged to ensure overall development of students. After school, students can organize some English speech or debate competition, aiming at improving interest in English.

\section{Strengthen Management of the Learning Process}

The teachers in such new learning concept has transformed into a guider, which means that teachers can conduct necessary regulatory and correcting errors through their own observations and inquiries and carry out some guidance for learning methods of students instead of out of such learning activity. Meanwhile, teachers can guide students' learning process. The following points shall be done for achieving success of students in learning. First is that any problems and errors will be occurred during independent study, including problems in English grammar, learning method, etc.. For these problems and errors, teacher shall be conduct correction in time. Meanwhile, teachers shall develop a learning method that is suitable for development of some group, aiming at guiding students in a correct learning path. Second is that the voice of students in discuss some problems in differences is too large in such cooperative learning mechanism, which may be affect discussion and learning of other groups. In this case, teachers shall stop such situation in time and ask that group discuss in a low voice, so as not to affect the normal learning of other students. Third is that teachers shall encourage students to actively speak in class. May be sometimes external factors will affect speak in class of students, teachers shall allow groups to prepare some English materials in advance for using in speak in class. In addition, teachers shall encourage students to brave speak in class and give moral stimulation to students who make speak in class as well as give some guidance on speaking skill.

\section{Correctly Grasp the Opportunity to Ask Questions}

Learning within the group needs teachers' supervision. In this process, teachers can put forward some constructive problems for students to improve students' learning ability. Based on this, the teacher should do the following points. First is that problem shall be targeted. Each student has different focus on same knowledge, which requires teachers shall put forward appropriate problem according to real situation. Second is that some time for thinking and finding answers shall be given after issuing problems. If student has no means to solve such problem, teachers can give some tips and inspiration. Third is teachers shall give assessment for answer of students no matter what the result after answering question. Praise shall be given for good results and explanation shall be given for problem where none exists to prevent recurrence of similar problems.

\section{Correct evaluation of learning effect}

The result of cooperative learning shall be achieved expected results at least. Hence, it is a very meaningful thing for analyzing final results. And evaluation and analysis can be divided into the following forms. First is group internal evaluation, including summarizing existed problems and insisting on good points. Second is mutual evaluation of groups that can increase the quality of the evaluation and let all the students involve in learning. Third is that teacher gives evaluation and analysis for final results. For the good performance, teachers shall give praise and encourage students to learn it. For bad performance, teachers shall give explanation in a subtle way to prevent student from reducing study enthusiasm.

\section{Conclusion}

With development of society, updating of educational concept, the major direction of education reform has been gradually covered improvement of students' autonomous learning awareness, strengthening of the cultivation of innovative consciousness and cultivation of team spirit. Under such new education background, teachers shall adapt it as soon as possible instead of scholasticism. Cooperative learning is not only a kind of education mode, which can improve students' basic quality and bring great help to promotion of comprehensive ability of students. However, cooperative skills 
of cooperative learning needs to be improve. The chaotic classroom is a factor that could not be ignored in future education reform.

\section{References}

[1] Guo Lan. Problems and Countermeasure for Cooperative Learning of Junior Middle School English. Journal of Weifang Engineering Vocational College, 2011, (01) : 112-115.

[2] Jiang Youwei, Liu Zhijuan, Zhang Li. Research on College English Cooperative Learning Mode Based on Tasks. Humor and the Humorist, 2010, (7) : 142-144

[3] Deng Huilan. Analyze Function and Implementation Path of Cooperative Learning in English Teaching. Democratic Classroom, 2013, (8):255-256

[4] Xue Chunlin. Several Issues About Autonomous-Cooperative Study of College English. Journal of the College of Northwest Adult Education, 2009, (04):61-62 